\title{
Prevalence of micro- and macroalbuminuria, arterial hypertension, retinopathy and large vessel disease in European Type 2 (non-insulin-dependent) diabetic patients
}

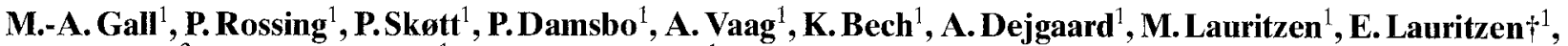 \\ P.Hougaard ${ }^{2}$, H. Beck-Nielsen ${ }^{1}$ and H.H.Parving ${ }^{1}$ \\ ${ }^{1}$ Hvidöre Hospital, Klampenborg, and ${ }^{2}$ Novo Research Institute, Bagsvaerd, Denmark
}

\begin{abstract}
Summary. The prevalence of micro- and macroalbuminuria was determined in Type 2 (non-insulin-dependent) diabetic patients, less than 76 years of age, attending a diabetic clinic during 1987. All eligible patients $(n=557)$ were asked to collect a 24-h urine sample for quantitative albumin analysis. Urine collections were obtained in 296 males and $253 \mathrm{fe}$ males $(96 \%)$. Normoalbuminuria were defined as urinary albumin excretion $\leq 30 \mathrm{mg} / 24 \mathrm{~h}(n=323)$, microalbuminuria as $31-299 \mathrm{mg} / 24 \mathrm{~h}(n=151)$, and macroalbuminuria as $\geq$ $300 \mathrm{mg} / 24 \mathrm{~h}(n=75)$. The prevalence of macroalbuminuria was significantly higher in males $(20 \%)$ than in females $(6 \%)$, while the prevalence of microalbuminuria was almost identical in males (26\%) and females (29\%). The prevalence of arterial hypertension increased with increased albuminuria, being $48 \%, 68 \%$, and $85 \%$ in patients with normoalbuminuria, microalbuminuria, and macroalbuminuria respectively. Prevalence of proliferative retinopathy rose with increasing albuminuria, being $2 \%, 5 \%$ and $12 \%$ in patients with normoalbuminuria, microalbuminuria, and macroalbuminuria respectively. Prevalence of coronary heart disease, based on
\end{abstract}

Minnesota coded electrocardiograms, was more frequent in patients with macroalbuminuria ( $46 \%$ ) compared to patients with microalbuminuria ( $26 \%$ ) and patients with normoalbuminuria (22\%). Foot ulcers were more frequent in microand macroalbuminuric patients, being $13 \%$ and $25 \%$, respectively, compared to $5 \%$ in patients with normoalbuminuria. This cross-sectional study has revealed a high prevalence of microalbuminuria (27\%) and macroalbuminuria (14\%) in Type 2 diabetic patients. Patients with raised urinary albumin excretion are characterized by obesity, elevated haemoglobin $\mathrm{A}_{1 c}$, increased frequency of arterial hypertension, proliferative retinopathy, coronary heart disease and foot ulcers. Thus, these findings suggest that urinary excretion of albumin should be monitored routinely in patients with Type 2 diabetes.

Key words: Type 2 (non-insulin-dependent) diabetes mellitus, microalbuminuria, macroalbuminuria, arterial hypertension, retinopathy, macroangiopathy.
Recent longitudinal studies have revealed a cumulative incidence of proteinuria between 30 and $50 \%$ in Type 2 (non-insulin-dependent) diabetic patients of different ethnic origins [1-3]. Diabetic nephropathy is the single most important cause of end-stage renal disease in the western world, accounting for more than $25 \%$ of all endstage renal disease in the United States [4]. Approximately $50 \%$ of the diabetic patients with end-stage renal disease suffer from Type 2 diabetes $[5,6]$. The cost of caring for patients with end-stage renal disease in the United States currently exceeds 0.8 billion US dollars per year for diabetic nephropathy alone and is rising rapidly. Ninetyseven percent of the excess mortality associated with Type 2 diabetes in the Pima Indians, has been found in patients with proteinuria [7].

Mogensen et al. [8] have shown that raised urinary albumin excretion below the level of clinical albuminuria
(Albustix), so-called microalbuminuria, predicts the development of persistent macroalbuminuria in patients with Type 2 diabetes. Follow-up studies in Type 2 diabetic patients have demonstrated that microalbuminuria is a strong predictor of all-cause mortality, mainly cardiovascular [8-10].

The aim of this cross-sectional study was to determine the prevalence of micro- and macroalbuminuria in Type 2 diabetic patients below the age of 76 years, attending a diabetic clinic in Copenhagen, and to evaluate the relationship between urinary albumin excretion and arterial blood pressure, retinopathy, blindness, macroangiopathy and foot ulcers. The study was started in 1987 as part of a prospective study on the development of diabetic nephropathy, retinopathy and cardiovascular disease in relation to abnormal urinary albumin excretion rate. 
Table 1. Clinical data and prevalence of normo-, micro- and macroalbuminuria in 549 patients with Type 2 (non-insulin-dependent) diabetes

\begin{tabular}{|c|c|c|c|c|c|c|c|c|c|}
\hline & $\begin{array}{l}\text { No of } \\
\text { patients }\end{array}$ & $\begin{array}{l}\text { Prevalence } \\
\text { of total }(\%) \\
(95 \% \text { confi- } \\
\text { dence interval) }\end{array}$ & $\begin{array}{l}\text { Sex ratio } \\
\text { (men/ } \\
\text { women) }\end{array}$ & $\begin{array}{l}\text { Mean (SD) } \\
\text { age } \\
\text { (years) }\end{array}$ & $\begin{array}{l}\text { Mean (SD) } \\
\text { known duration } \\
\text { of diabetes } \\
\text { (years) }\end{array}$ & $\begin{array}{l}\text { Anti-diabetic } \\
\text { treatment } \\
\text { d/oba } / i^{a} \\
(\%)\end{array}$ & $\begin{array}{l}\text { Median haemo- } \\
\text { globin } \mathrm{A}_{1 \mathrm{c}} \\
\text { (range) } \\
(\%)\end{array}$ & $\begin{array}{l}\text { Mean (SD) } \\
\text { serum crea- } \\
\text { tinine } \\
(\mu \mathrm{mol} / \mathrm{l})\end{array}$ & $\begin{array}{l}\text { Median albu- } \\
\text { minuria (range) } \\
\text { (mg/24 h) }\end{array}$ \\
\hline $\begin{array}{l}\text { Micro- } \\
\text { albuminuria }\end{array}$ & 151 & $27(24-31)$ & 1.04 & $61(10)$ & $10(7)$ & $25 / 44 / 31$ & $8.9(5.3-13.5)$ & $81(25)$ & $90(31-261)$ \\
\hline$p$ value & & & $\begin{array}{l}<0.001^{\mathrm{c}} \\
<0.001^{\mathrm{d}}\end{array}$ & & $\begin{array}{l}<0.005^{\mathrm{e}} \\
<0.005^{\mathrm{c}}\end{array}$ & & $\begin{array}{l}<0.001^{\mathrm{e}} \\
<0.001^{\mathrm{c}}\end{array}$ & $\begin{array}{l}<0.001^{\mathrm{c}} \\
<0.001^{\mathrm{d}}\end{array}$ & \\
\hline
\end{tabular}

a $\mathrm{d}=$ diet; oha $=$ oral hypoglycaemic agent; $\mathrm{i}=$ insulin; ${ }^{\mathrm{b}}$ Some patients with macroalbuminuria receiving antihypertensive treatment had albuminuria below $300 \mathrm{mg} / 24 \mathrm{~h}$; ${ }^{c}$ Normoalbuminuria vs mac- roalbuminuria; ' Microalbuminuria vs macroalbuminuria; ${ }^{\mathrm{A}}$ Normoalbuminuria vs microalbuminuria

recorded at the disappearance of the Korotkoff sounds (phase V). Arterial hypertension was diagnosed according to the World Health Organization's criteria, systolic blood pressure $\geq 160 \mathrm{~mm} \mathrm{Hg}$, and/or diastolic blood pressure $\geq 95 \mathrm{~mm} \mathrm{Hg}$, or if antihypertensive treatment was being prescribed.

A 12-lead ECG was recorded. The ECG was coded independently by two trained observers using the Minnesota codes [14]. Coronary heart disease was diagnosed if ECG showed signs of probable myocardial infarction (Minnesota-code 1.1-2) or possible myocardial ischaemia (Minnesota-code 1.3, 4.1-4, 5.1-3 or 7.1).

Ophthalmoscopy through dilated pupils was carried out by the same observer (EL). Visual acuity was assessed through a pin-hole. Blindness was defined as a corrected visual acuity $\leq 0.1(6 / 60)$ in the best eye. treated lean patients $\left(\mathrm{BMI}<25 \mathrm{~kg} / \mathrm{m}^{2}\right.$ in females, BMI $<27 \mathrm{~kg} / \mathrm{m}^{2}$ in males) had a glucagon test performed, and Type 2 diabetes was diagnosed if a stimulated C-peptide value was $\geq 0.60 \mathrm{pmol} / \mathrm{ml}$ [11]. The glucagon/C-peptide test was carried out after an overnight fast. Blood samples for plasma C-peptide determination were obtained before and $6 \mathrm{~min}$ after an $\mathrm{i}$. v. bolus injection of $1 \mathrm{mgglucagon}$ (Novo, Bagsvaerd, Denmark) as described previously [12]. In 110 lean diabetic patients the glucagon test was performed. Seventy diabetic patients were excluded, since the glucagon test showed a stimulated $\mathrm{C}$-peptide value of less than $0.60 \mathrm{pmol} / \mathrm{ml}$. The remaining $572 \mathrm{pa}-$ tients were invited to participate in the study. Fifteen patients were excluded, mainly due to disabling diseases such as dementia and sequelae of cerebro-vascular accidents (CVA), which made them unable to co-operate. All the remaining eligible patients $(n=557)$ were asked to collect a 24 -h urine sample for analysis of albumin excretion; 549 patients $(96 \%)$ complied. Table 1 shows the clinical data for these patients.

The experimental design was approved by the local ethical committee, and all patients gave their informed consent.

\section{Methods}

All participants were examined and interviewed by one of us (M-A G). The World Health Organization cardiovascular questionnaire [13] was used to assess past and present evidence of myocardial infarction, angina pectoris, CVA, transient cerebral ischaemic attack and peripheral vascular disease. Evidence of present or previous foot ulcers, present medication and smoking habits was also recorded. Smokers were defined as persons smoking more than one cigarette/cigar/pipe per day, all others being classified as non-smokers.

Arterial blood pressure was measured twice, on the right arm, after $10 \mathrm{~min}$ rest in the supine position. The measurements were carried out with a Hawksley random zero sphygmomanometer (Hawksley \& Sons Ltd, Lancing, Sussex, UK), cuff size $25 \times 12 \mathrm{~cm}$ in lean and $30 \times 15 \mathrm{~cm}$ in obese patients. Diastolic blood pressure was

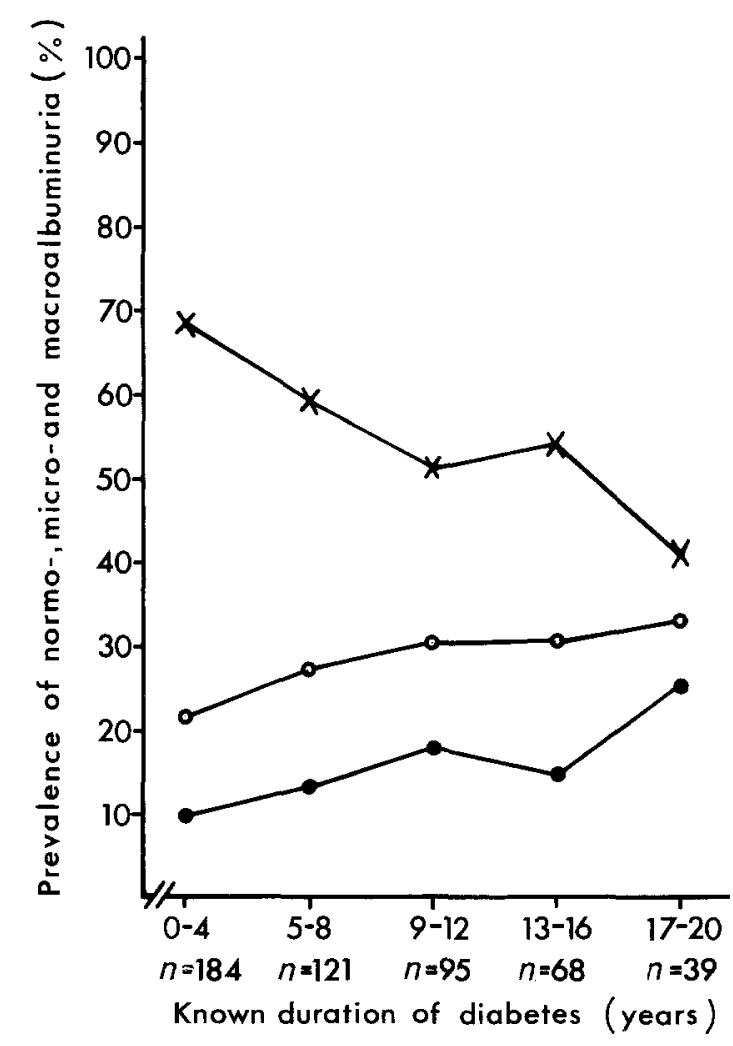

Fig. 1. Prevalence of albuminuria in relation to known duration of Type 2 (non-insulin-dependent) diabetes. $X=$ normoalbuminuria, $\mathrm{O}=$ microalbuminuria, $\boldsymbol{O}=$ macroalbuminuria 
Table 2. Prevalence of arterial hypertension and antihypertensive treatment, and measurement of arterial blood pressure in relation to urinary albumin excretion in 549 patients with Type 2 (non-insulin-dependent) diabetes. Values in parentheses are $95 \%$ confidence intervals

\begin{tabular}{llll}
\hline & $\begin{array}{l}\text { Prevalence of hypertension } \\
(\%)\end{array}$ & $\begin{array}{l}\text { Prevalence of antihypertensive } \\
\text { treatment } \\
(\%)\end{array}$ & $\begin{array}{l}\text { Mean (SD) arterial blood pressure } \\
\text { in untreated patients } \\
(\mathrm{mm} \mathrm{Hg})\end{array}$ \\
\hline $\begin{array}{l}\text { Normoalbuminuria } \\
(n=323)\end{array}$ & $48(43-54)$ & $30(25-35)$ & $145 / 80(21 / 10)(n=226)$ \\
$\begin{array}{l}\text { Microalbuminuria } \\
(n=151)\end{array}$ & $68(60-76)$ & $39(31-47)$ & $157 / 83(22 / 11)(n=92)$ \\
$\begin{array}{l}\text { Macroalbuminuria } \\
(n=75)\end{array}$ & $85(75-92)$ & $65(53-76)$ & $161 / 83(25 / 11)(n=26)$ \\
$p$ value & $<0.001^{\mathrm{s}}$ & $<0.001^{\mathrm{d}}$ & $<0.001^{\mathrm{f}}$ \\
& $<0.005^{\mathrm{b}}$ & $<0.001^{\mathrm{e}}$ & $<0.001^{\mathrm{g}}$ \\
& $<0.005^{\mathrm{c}}$ & $<0.05^{\mathrm{h}}$
\end{tabular}

a Normoalbuminuria vs microalbuminuria: $\chi_{\mathrm{MH}}^{2}=14.4, \mathrm{df}=1$; b Normoalbuminuria vs macroalbuminuria: $\chi_{\mathrm{MH}}^{2}=32.3, \mathrm{df}=1$; ${ }^{c}$ Microalbuminuria vs macroalbuminuria: $\chi^{2} \mathrm{MH}=9.0, \mathrm{df}=1 ;{ }^{\mathrm{d}}$ Normoalbuminuria vs macroalbuminuria: $\chi_{\mathrm{MH}}^{2}=32.0, \mathrm{df}=1$; ${ }^{\mathrm{e}}$ Microal-

The 24-h urine volume was recorded and aliquots stored at $-20^{\circ} \mathrm{C}$ until the albumin concentration was determined, within one month, by radioimmunoassay with a single antibody [15]. This assay has a sensitivity of $0.5 \mathrm{mg} / \mathrm{l}$ and an interassay coefficient of variation of $9 \%$. Sterility of urine was checked by quantitative culture. If bacterial growth was found, urine collection was repeated after treatment. Normoalbuminuria was defined as urinary albumin excretion rate $\leq 30 \mathrm{mg} / 24 \mathrm{~h}$, microalbuminuria as urinary albumin excretion rate greater than $30 \mathrm{mg} / 24 \mathrm{~h}$ and less than $300 \mathrm{mg} / 24 \mathrm{~h}$, and macroalbuminuria as urinary albumin excretion rate $\geq 300 \mathrm{mg} / 24 \mathrm{~h}$ as defined at a previous consensus conference [16]. Some patients with macroalbuminuria receiving antihypertensive treatment had aibuminuria below $300 \mathrm{mg} / 24 \mathrm{~h}$.

Venous blood samples were collected in the non-fasting state. Haemoglobin $A_{1 c}$ concentration (normal range 4.1-6.1\%) was measured by an isoelectric focusing method [17]. Serum creatinine concentration was assayed by a buffered kinetic Jaffe' method [18].

BMI was calculated as: body mass index $=$ weight $(\mathrm{kg}) /$ height $(m)^{2}$.

\section{Statistical analyses}

Values are mean (SD) or median (range). For evaluating frequencies the chi-squared test was used. The complications studied are irreversible, or almost irreversible, and therefore their prevalence increases with time, except when modified by the excess mortality in patients with elevated urinary albumin excretion rate. To account for the effect of duration of disease in comparisons of complications we performed stratified Mantel-Haenszel analyses [19], using intervals of known duration of diabetes of $0-4,5-8,9-12,13-16$, and 1720 years. To indicate when Mantel-Haenszel analyses has been applied, a subscript $\mathrm{MH}$ is added to chi-square.

In comparison of continuous variables the Kruskal-Wallis test of variance was used in order to test for differences between the three groups. If differences were found, the Mann-Whitney test was used for comparison between two groups.

Multiple logistic regression analyses [20] were used to assess the association of various factors to the occurrence of albuminuria, and the occurrence of coronary heart disease. The multiple logistic regression analysis was performed with sex, age, known duration of diabetes, $\mathrm{BMI}$, haemoglobin $\mathrm{A}_{1 c}$, serum-creatinine, presence of coronary heart disease, systolic and diastolic pressures, presence of smoking, retinopathy and maculopathy, foot ulcers and intermittent claudication, transient cerebral ischaemic attack and CVA as independent variables, and normo- micro- and macroalbuminuria as the dependent variables. In the case of albuminuria where there buminuria vs macroalbuminuria: $\chi_{M H}^{2}=16.1, \mathrm{df}=1$; ${ }^{\mathrm{f}}$ Systolic blood pressure, normoalbuminuria vs microalbuminuria; s Systolic blood pressure, normoalbuminuria vs macroalbuminuria; h Diastolic blood pressure, normoalbuminuria vs microalbuminuria

are three ordinal categories, the cumulative logit model [20, section 6.3] has been used. An assumption of this model is that the odds ratio for normo- vs micro- and macroalbuminuria is the same as for normo- and micro- vs macroalbuminuria. The confidence intervals are based on the asymptotic standard error of the logarithm of the odds ratio. The significant variables were selected by a likelihood based forward stepwise method. A multiple logistic regression analysis was performed with the same variables as mentioned above (except presence of coronary heart disease which was ex-

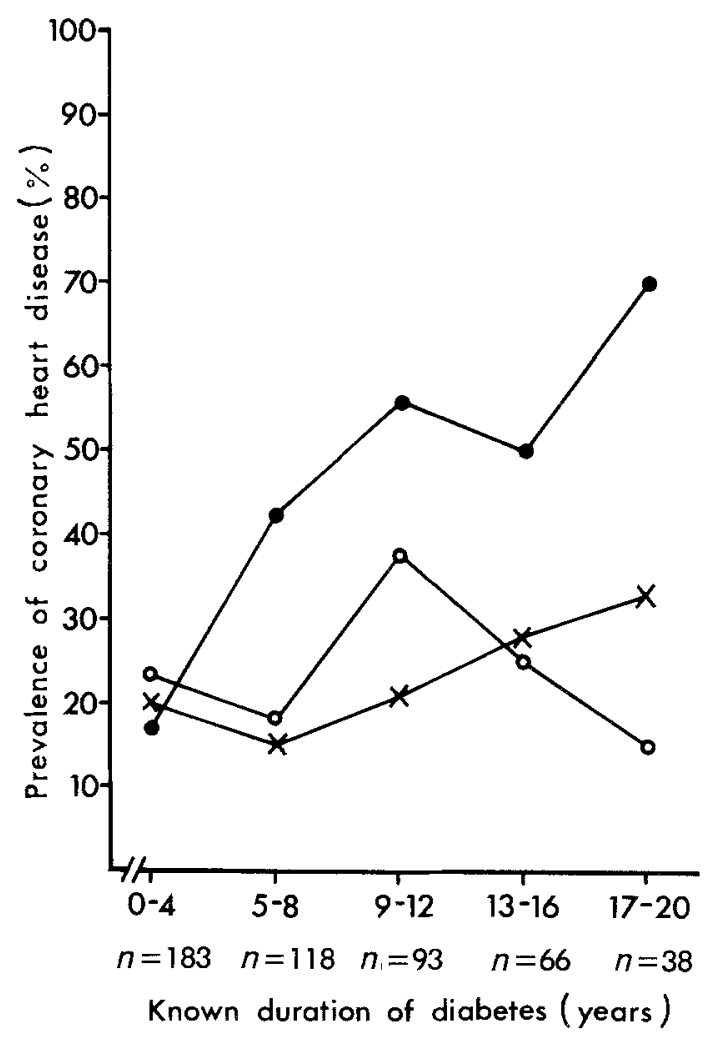

Fig. 2. Prevalence of coronary heart disease (based on ECG Minnesota codes) in relation to known duration of Type 2 (non-insulindependent) diabetes and level of urinary albumin excretion rate. $\mathrm{X}$ = normoalbuminuria, $\quad \mathrm{O}=$ microalbuminuria, $\quad \mathbf{O}=$ macroal buminuria 
Table 3. Prevalence of diabetic retinopathy and blindness in relation to urinary albumin excretion in 549 patients with Type 2 (noninsulin-dependent) diabetes. Values in parentheses are $95 \%$ confidence intervals

\begin{tabular}{lllll}
\hline & \multicolumn{2}{l}{ Prevalence of retinopathy } & $\begin{array}{l}\text { Prevalence of } \\
\text { blindness }\end{array}$ \\
\cline { 2 - 5 } & $\begin{array}{l}\text { Proliferative } \\
(\%)\end{array}$ & $\begin{array}{l}\text { Simple } \\
(\%)\end{array}$ & $\begin{array}{l}\text { None } \\
(\%)\end{array}$ & $(\%)$ \\
\hline $\begin{array}{l}\text { Normoalbuminuria } \\
(n=323)\end{array}$ & $2(1-4)$ & $25(21-31)$ & $73(67-78)$ & $1(0-3)$ \\
$\begin{array}{l}\text { Microalbuminuria } \\
(n=151)\end{array}$ & $5(2-9)$ & $43(35-51)$ & $52(44-61)$ & $2(0-6)$ \\
$\begin{array}{l}\text { Macroalbuminuria } \\
p \text { value }\end{array}$ & $\begin{array}{l}12(6-22) \\
<0.01^{\mathrm{a}}\end{array}$ & $33(23-46)$ & $55(43-67)$ & $5(1-13)$ \\
\hline
\end{tabular}

${ }^{a}$ Normoalbuminuria vs microalbuminuria: $\chi_{\mathrm{MH}}^{2}=14.6, \mathrm{df}=4$;

b Normoalbuminuria vs macroalbuminuria: $\chi_{\mathrm{MH}}^{2}=26.0, \mathrm{df}=4$

changed with urinary albumin excretion rate $(\mathrm{mg} / 24 \mathrm{~h})$ ) as independent variables, and occurrence of coronary heart disease as the dependent variable.

A $p$ value $<0.05$ was considered significant.

\section{Results}

Our cross-sectional study showed a prevalence of microalbuminuria and macroalbuminuria of $27 \%$ and $14 \%$, respectively (Table 1 ). The prevalence of macroalbuminuria was four times higher in males compared to females $(p<0.001)$, while the prevalence of normo- and microalbuminuria was almost identical in males and females. Of the 151 patients with microalbuminuria, 51 patients had urinary albumin excretion rate $\geq 100 \mathrm{mg} / 24 \mathrm{~h}$. Patients with abnormal urinary albumin excretion rate had slightly longer known duration of diabetes and elevated haemoglobin $\mathrm{A}_{1 \mathrm{c}}(p<0.001)$ as compared to the normoalbuminuric subjects. The anti-diabetic treatment was comparable in all three groups. BMI was higher in patients with microalbuminuria: $28.6(\mathrm{SD} 4.5) \mathrm{kg} / \mathrm{m}^{2}$ and macro- albuminuria: $29.6(5.4) \mathrm{kg} / \mathrm{m}^{2}$ compared to patients with normoalbuminuria: $27.2(4.8) \mathrm{kg} / \mathrm{m}^{2}(p<0.01)$.

Figure 1 shows the relationship between known duration of diabetes and albuminuria. The prevalence of normoalbuminuria declined from $68 \%$ to $41 \%$ at 20 years duration of diabetes. The prevalence of microalbuminuria increased from 22 to $33 \%$, and the prevalence of macroalbuminuria rose from 10 to $26 \%$ after a 20 -year duration of diabetes.

Bacteriuria of more than $10^{5}$ microorganisms per $\mathrm{ml}$ was rare in males $(2 \%)$, but fairly common in females; $8 \%$, $18 \%$ and $14 \%$ in normo- micro- and macroalbuminuria respectively.

The prevalence of arterial hypertension, antihypertensive treatment, and blood pressure levels in patients not receiving antihypertensive treatment are shown in Table 2. The prevalence of arterial hypertension was high in all three groups, and increased with increasing albuminuria. Untreated systolic blood pressure was higher in patients with microalbuminuria and with macroalbuminuria compared to patients with normal albumin excretion $(p<0.001$, Table 2$)$. A slightly elevated diastolic blood pressure, in patients with microalbuminuria compared to normoalbuminuria, was also observed $(p<0.05)$. When adjustment for BMI, age, and sex was carried out systolic blood pressure remained significant $(p<0.001)$ while diastolic blood pressure failed $(p=0.07)$. Linear regression analysis, in patients not receiving antihypertensive treatment showed that systolic $(r=0.27, p<0.001)$ and diastolic $(r=0.24, p<0.01)$ blood pressure correlated with the urinary albumin excretion rate.

The prevalence of proliferative retinopathy rose with increasing urinary albumin excretion $(p<0.01$, Table 3$)$. Maculopathy was more frequent in patients with macroalbuminuria: $13 \%$ compared to patients with normoalbuminuria: $4 \%$ and patients with microalbuminuria: $5 \%$ $(p<0.05)$. However, $55 \%$ of patients with macroalbuminuria did not suffer from retinopathy.

Figure 2 shows the prevalence of coronary heart disease, based on ECG Minnesota codes, in relation to

Table 4. Prevalence of coronary heart disease (based on ECG Minnesota codes), angina pectoris, cerebro-vascular accident (CVA), transient cerebral ischaemic attack (TIA), intermittent claudication, and foot ulcers in relation to urinary albumin excretion in 549 patients with Type 2 (non-insulin-dependent) diabetes. Values in parentheses are $95 \%$ confidence intervals

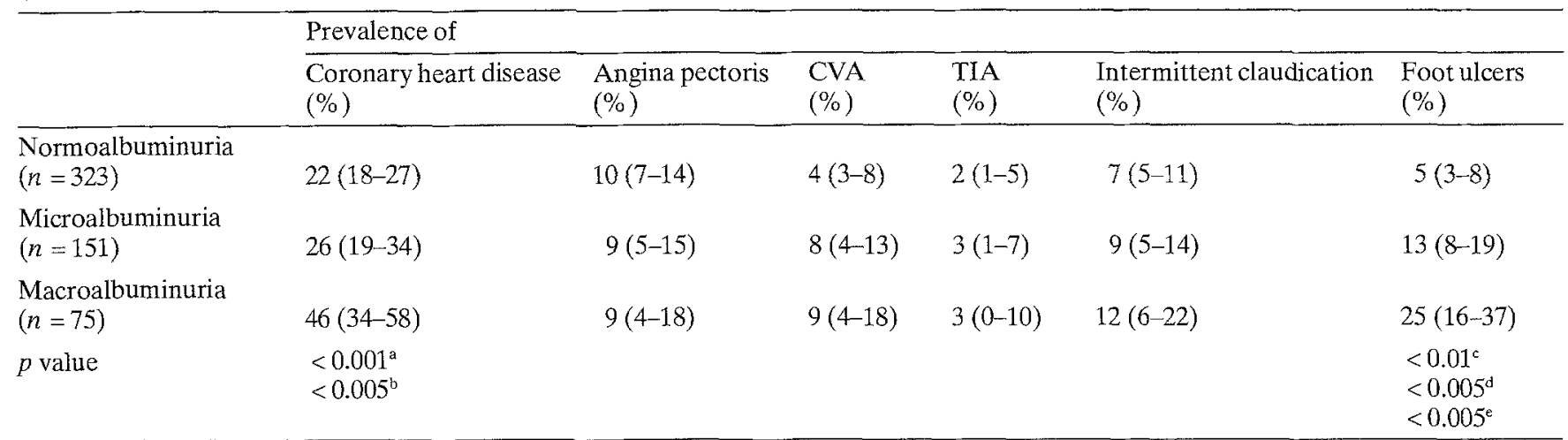

a Normoalbuminuria vs macroalbuminuria: $\chi_{\mathrm{MH}}^{2}=22.6$, $\mathrm{df}=5$;

b Microalbuminuria vs macroalbuminuria: $\chi_{\mathrm{MH}}^{2}=19.2, \mathrm{df}=5$;

' Normoalbuminuria vs microalbuminuria: $\chi_{\mathrm{MH}}^{2}=7.9, \quad \mathrm{df}=1$;
${ }^{\mathrm{d}}$ Microalbuminuria vs macroalbuminuria: $\chi^{2} \mathrm{MH}=8.0, \mathrm{df}=1$; ${ }^{\mathrm{e}}$ Normoalbuminuria vs macroalbuminuria: $\chi_{\mathrm{MF}}^{2}=28.6, \mathrm{df}=1$ 
Table 5. Adjusted odds ratios ( $95 \%$ confidence interval) for albuminuria in Type 2 (non-insulin-dependent) diabetic patients, by means of multiple ordinal logistic analysis

\begin{tabular}{lll}
\hline Variable & Odds ratio & Probability \\
\hline Male sex & $1.87(1.25-2.79)$ & $<0.01$ \\
Body mass index $\left(\mathrm{kg} / \mathrm{m}^{2}\right)$ & $1.10(1.06-1.15)$ & $<0.001$ \\
Retinopathy & $1.26(1.04-1.53)$ & $<0.01$ \\
Foot ulcer & $2.73(1.46-5.10)$ & $<0.01$ \\
Haemoglobin $\mathrm{A}_{1 \mathrm{c}}(1 \%)$ & $1.25(1.13-1.38)$ & $<0.001$ \\
Serum creatinine $(10 \mu \mathrm{mol} / \mathrm{l})$ & $1.19(1.09-1.28)$ & $<0.001$ \\
Systolic blood pressure $(10 \mathrm{~mm} \mathrm{Hg})$ & $1.20(1.10-1.30)$ & $<0.001$ \\
Coronary heart disease & $1.59(1.06-2.40)$ & $<0.05$ \\
\hline
\end{tabular}

Serum creatinine and systolic blood pressure expressed as multiples of 10 units such that odds ratio is calculated for a 10 unit change in these variables. According to the model the same odds ratio applies for the comparison normo- vs micro- and macroalbuminuria as for normo- and micro- vs macroalbuminuria

Table 6. Adjusted odds ratios ( $95 \%$ confidence interval) for coronary heart disease in Type 2 (non-insulin-dependent) diabetic patients by means of multiple ordinal logistic analysis

\begin{tabular}{lll}
\hline Variable & Odds ratio & Probability \\
\hline Age $(10$ years) & $1.68(1.35-2.10)$ & $<0.001$ \\
Known duration of diabetes (1 year) & $1.04(1.01-1.07)$ & $<0.01$ \\
Transient cerebral ischaemic attack & $3.40(1.05-10.70)$ & $<0.05$ \\
Microalbuminuria & $1.06(0.66-1.70)$ & $=0.80$ \\
Macroalbuminuria & $3.20(1.80-5.60)$ & $<0.001$ \\
\hline
\end{tabular}

Age expressed as multiple of 10 units such that odds ratio is calculated for a 10 unit change in this variable

known duration of diabetes and type of albuminuria. A higher prevalence of coronary heart disease and a significant increase with longer duration of diabetes was demonstrated in macroalbuminuric patients compared to patients with normoalbuminuria $(p<0.001)$ and microalbuminuria $(p<0.005$, Fig. 2 and Table 4$)$. Despite this difference in the prevalence of coronary heart disease, the World Health Organization cardiovascular questionnaires revealed no differences in the frequency of angina pectoris between the three groups. The prevalence of CVA, transient cerebral ischaemic attack and intermittent claudication was low, and not significantly different between the three groups. The past and present prevalence of foot ulcers was higher in patients with $(25 \%)$ than without macroalbuminuria $(p<0.01$, Table 4$)$. No significant difference in the history of smoking was found, the frequency of current smokers being $39 \%, 38 \%$, and $42 \%$ in patients with normoalbuminuria, microalbuminuria and macroalbuminuria, respectively.

Multiple logistic regression analysis was performed with sex, age, known duration of diabetes, BMI, haemoglobin $\mathrm{A}_{1 \mathrm{c}}$, serum-creatinine, presence of coronary heart disease, systolic and diastolic pressures, presence of smoking, retinopathy and maculopathy, foot ulcers and intermittent claudication, transient cerebral ischaemic attack and CVA as independent variables, and normo- microand macroalbuminuria as the dependent variables. The odds ratio and $95 \%$ confidence interval, for variables with significant influence on albuminuria, are shown in Table 5. Male sex, BMI, retinopathy, foot ulcer, haemoglobin $\mathrm{A}_{1 \mathrm{c}}$, serum-creatinine, systolic blood pressure and presence of coronary heart disease were significantly, independently associated with albuminuria. A multiple logistic regression analysis was performed with the same variables as mentioned above (except presence of coronary heart disease which was exchanged with urinary albumin excretion rate $(\mathrm{mg} / 24 \mathrm{~h})$ ) as independent variables and occurrence of coronary heart disease as the dependent variable. In Table 6 the odds ratio and $95 \%$ confidence interval are shown. In this analysis age, known duration of diabetes, transient cerebral ischaemic attack and albuminuria were independently associated with the presence of coronary heart disease. To examine the sex effect stratified analyses were made for each sex, but for no variable was there a significant difference. There was, however a tendency towards a greater effect of the variables for males, i. e. larger male risk differences.

\section{Discussion}

The definition of micro- and macroalbuminuria applied in our study is identical to that recommended recently at a consensus conference [16]. Our cross-sectional study revealed an overall prevalence of microalbuminuria of $27 \%$ and of macroalbuminuria of $14 \%$ in Type 2 diabetic patients less than 76 years of age. Our patients with raised urinary albumin excretion were characterized by a longer duration of diabetes, obesity, elevated haemoglobin $\mathrm{A}_{\mathrm{lc}}$, increased prevalence of arterial hypertension, proliferative retinopathy and maculopathy, coronary heart disease and foot ulcers.

As our study was not a survey based on the general population, selection bias might have been a confounding variable. However, none of our patients were referred to the hospital due to microalbuminuria, because sensitive techniques for determining urinary albumin concentration were not available to the general practitioners or general hospitals in 1987. However, we cannot rule out the possibility of selective referral of patients with late complications, e.g. nephropathy, since 27\% (16 males/4 females) of our patients with macroalbuminuria had nephropathy at the time of referral. However, the prevalence of macroalbuminuria in relation to known duration of Type 2 diabetes agrees closely with the results obtained in two surveys based on the general population, revealing a prevalence of macroalbuminuria of $12 \%$ and $15 \%$, respectively $[21,22]$. An even higher prevalence of macroalbuminuria $(21 \%)$ has been demonstrated in the Pima Indians [23]. Other ethnic groups, e. g. Blacks, Hispanics and Indians, also have a higher prevalence of raised urinary albumin excretion as compared to European patients [24-26]. We have no evidence suggesting that the patients who dropped out were unrepresentative of the group as a whole except those with raised albumin excretion rate (excess mortality).

If microalbuminuria is a predictor or a marker of progression to clinical albuminuria as originally suggested by Mogensen [8], then its prevalence should be higher than that of macroalbuminuria early in the course of Type 2 diabetes. The present and the previous studies $[8,9,22,27]$ have clearly shown that this is the case. Ballard et al. [3] 
have demonstrated that the cumulative incidence of persistent proteinuria is $25 \% 20$ years after the diagnosis of Type 2 diabetes. Persistent proteinuria was present in $8 \%$ of the patients even at the time of diagnosis. We found that $10 \%$ of our patients developed macroalbuminuria within the first 4 years of diabetes, a finding in close agreement with the results obtained in a study of 661 patients with Type 2 diabetes based on the general population [21]. Preliminary data from a kidney biopsy study indicate that all albuminuric Type 2 diabetic patients with diabetic retinopathy suffered from diabetic glomerulosclerosis, while the chance for a diabetic or non-diabetic glomerulopathy was $50 \%$ in albuminuric Type 2 diabetic patients without retinopathy [28]. The male predominance of proteinuric patients was more marked in our study as compared to previous investigations $[3,21,22]$.

Our study revealed a higher frequency of raised arterial blood pressure in patients with microalbuminuria and macroalbuminuria. This finding confirms and extends previous observations in Type 2 diabetes [9, 23, 27, 29]. Furthermore, $48 \%$ of the normoalbuminuric diabetic group had arterial hypertension, suggesting a high prevalence of essential hypertension. Raised blood pressure accelerates the development and the progression of nephropathy in Type 2 diabetic patients [30-32]. Arterial blood pressure thus seems to have a complex relationship with diabetic nephropathy - nephropathy raising blood pressure and blood pressure accelerating the course of nephropathy. Unfortunately, trials assessing the long-term impact on kidney function of effective antihypertensive treatment are still lacking in Type 2 diabetic patients with raised urinary albumin excretion rate.

Haemoglobin $\mathrm{A}_{1 c}$ and $\mathrm{BMI}$ were both elevated in our diabetic patients with raised urinary albumin excretion as compared to the normoalbuminuric patients. Furthermore, multiple logistic regression analysis revealed that both variables emerged as predictors of albuminuria. Longitudinal studies have demonstrated that hyperglycaemia is a risk factor for the development of proteinuria in Type 2 diabetes [3,33]. Long-term near-normal blood glucose concentrations may delay or even prevent the progression from microalbuminuria to macroalbuminuria in Type 1 diabetic patients $[34,35]$. Randomized controlled trials evaluating this important issue are urgently needed in Type 2 diabetic patients.

Our study revealed an association between raised urinary albumin excretion rate and the prevalence of maculopathy and proliferative retinopathy, in agreement with previous observations $[3,9,21,27]$. Of our patients with macroalbuminuria $55 \%$ were without retinopathy as compared to $62 \%$ and $60 \%$ of the diabetic patients investigated by Marshall et al. [27] and Schmitz et al. [9]. These findings are remarkable compared to Type 1 diabetic patients where only $1 \%$ of the proteinuric patients are without retinopathy [36].

Longitudinal follow-up studies in Type 2 diabetic patients [8-10] and in non-diabetic subjects [37, 38] have shown that microalbuminuria is a strong predictor of allcause mortality, mainly cardiovascular. Our study revealed that age, known duration of diabetes and abnormal urinary albumin excretion rate were associated with co- ronary heart disease when a logistic regression analysis was applied on all measured variables. Mattock et al. [39] showed that the urinary albumin excretion rate was significantly associated with coronary heart disease morbidity in normo- and microalbuminuric Type 2 diabetic patients. Of his patients $21 \%$ showed electrocardiographic evidence of coronary heart disease as compared with $22 \%$ and $26 \%$ in our normoalbuminuric and microalbuminuric group, respectively. The present and the previous study [39] both revealed that electrocardiographic signs of $\mathrm{co}^{-}$ ronary heart disease are approximately three to four times more frequent than symptoms (angina). Presence of autonomic neuropathy may contribute to this disparity. Conventional risk factors for cardiovascular disease cannot account for the association between elevated urinary albumin excretion and the cardiovascular mortality in Type 2 diabetic patients [40].

In conclusion, the present and previous studies suggest that urinary albumin excretion should be measured routinely in the management of patients with Type 2 diabetes because raised values indicate a need for more frequent follow-up of diabetic complications, coronary heart disease, arterial hypertension, and glycaemic control.

Acknowledgements. We are grateful for the technical work of Ms. U. Vonger and Ms. U. M. Smidt.

\section{References}

1. Sasaki A, Horiuchi N, Hasegawa K, Uehara M (1986) Risk factors related to the development of persistent albuminuria among diabetic patients observed in a long-term follow-up. J Jpn Diabetes Soc 29: 1017-1023

2. Kunzelman CL, Pettitt DJ, Bennett PH, Knowler WC (1985) Incidence of nephropathy in Type 2 diabetes mellitus. Am J Epidemiol 122: 547-548

3. Ballard DJ, Humphrey LL, Joseph Melton III I, Frohnert PP, Chu C, O'Fallon WM, Palumbo PJ (1988) Epidemiology of persistent proteinuria in Type II diabetes mellitus. Populationbased study in Rochester, Minnesota. Diabetes 37: 405-412

4. Eggers PW (1988) Effect of transplantation on the medicare endstage renal disease program. N Engl J Med 318: 223-229

5. Rettig B, Teutsch SM (1984) The incidence of end-stage renal disease in Type I and Type II diabetes mellitus. Diab Nephropath 3:26-27

6. Grenfell A, Bewick M, Parsons V, Snowden S, Taube D, Watkins PJ (1988) Non-insulin-dependent diabetes and renal replacement therapy. Diab Med 5: 172-176

7. Nelson RG, Pettitt DJ, Carraher MJ, Robert Baird H, Knowler WC (1988) Effect of proteinuria on mortality in NIDDM. Diabetes 37: 1499-1504

8. Mogensen CE (1984) Microalbuminuria predicts clinical proteinuria and early mortality in maturity-onset diabetes. N Engl $\mathbf{J}$ Med 310: 356-360

9. Schmitz A, Vaeth M (1988) Microalbuminuria: a major risk factor in Type 2 Diabetes. A 10-year follow-up study of 503 patients. Diab Med 5: 126-134

10. Jarrett RJ, Viberti GC, Argyropoulos A, Hill RD, Mahmud U, Murrells TJ (1984) Microalbuminuria predicts mortality in noninsulin-dependent diabetes. Diab Med 1: 17-19

11. Hother-Nielsen O, Faber O, Sørensen NS, Beck-Nielsen H (1988) Classification of newly diagnosed diabetic patients as insulin-requiring or non-insulin-requiring based on clinical and biochemical variables. Diab Care 11: 531-537 
12. Faber OK, Binder C (1977) C-peptide response to glucagon: a test for the residual $\beta$-cell function in diabetes mellitus. Diabetes 26: $605-610$

13. Rose G, Blackburn H, Gillum RF, Prineas RJ (1982) Cardiovascular survey methods. WHO Monograph Series No 56, Geneva, pp 162-165

14. Blackburn H, Keys A, Simonsen E, Rautaharju P, Punsar S (1960) The electrocardiogram in population studies: a classification system. Circulation 21: 1160-1175

15. Christensen C, Ørskov C (1984) Rapid screening PEG radioimmunoassay for quantitation of pathological microalbuminuria. Diab Nephropath 3: 92-94

16. Mogensen CE, Chachati A, Christensen CK et al. (1986) Microalbuminuria: an early marker of renal involvement in diabetes. Uremia Invest 9:85-95

17. Mortensen HB (1980) Quantitative determination of hemoglobin $A_{1 c}$ by thinlayer isoelectric focusing. J Chromatogr 182: 325-333

18. Ullmann R, Bonitz K (1976) Vollmechanisierte kinetische Messung von Kreatinin. Med Labor Bd 29: 137-145

19. Mantel N, Haenszel W (1959) Statistical aspects of the analysis of data from retrospective studies of disease. J Nat Cancer Inst 27: 719-748

20. Agresti A (1984) Analysis of ordinal categorical data. Wiley, New York

21. Klein R, Klein BEK, Moss S, DeMets DL (1988) Proteinuria in diabetes, Arch Intern Med 148: 181-186

22. Damsgaard EM, Mogensen CE (1986) Microalbuminuria in elderly hyperglycaemic patients and controls. Diab Med 3: 430-435

23. Nelson RG, Kunzelman CL, Pettitt DJ, Saad MF, Bennett PH, Knowler WC (1989) Albuminuria in Type 2 (non-insulin-dependent) diabetes mellitus and impaired glucose tolerance in Pima Indians. Diabetologia 32: 870-876

24. Knowler WC, Kunzelman CL (1988) Population comparison of the frequency of diabetic nephropathy. In: Mogensen CE (ed) The kidney and hypertension in diabetes mellitus. Nijhoff, Boston, pp 25-32

25. Haffner SM, Mitchell BD, Pugh JA et al. (1989) Proteinuria in Mexican Americans and non-hispanic whites with NIDDM. Diab Care 12:530-536

26. Samanta A, Burden AC, Feehally J, Walls J (1986) Diabetic renal disease: differences between Asian and white patients. Br Med J 293: 366-367

27. Marshall SM, Alberti KGMM (1989) Comparison of the prevalence and associated features of abnormal albumin excretion in insulin-dependent and non-insulin-dependent diabetes. Quart J Med 261: 61--71

28. Parving H-H, Gall M-A, Skøtt P, Jørgensen HE, Jørgensen F, Larsen S (1990) Prevalence and causes of albuminuria in noninsulin-dependent diabetic (NIDDM) patients. Kidney Int 37: 243 Abstract
29. Sasaki A, Horiuchi N, Hasagawa K, Uehara M (1989) Persistent albuminuria as an index of diabetic nephropathy in type 2 diabetic patients in Osaka, Japan - incidence, risk factors, prognosis and causes of death. Diab Res Clin Pract 7: 299-306

30. Knowler WC, Bennett PH, Nelson RG (1988) Prediabetic blood pressure predicts albuminuria after development of NIDDM. Diabetes 37 [Suppl]: 120 Abstract

31. Berkman J, Rifkin H (1973) Unilateral nodular diabetic glomerulosclerosis (Kimmelstiel-Wilson). Report of a case. Metabolism 22: 715-722

32. Beroniade VC, Lefebvre R, Falardeau P (1987) Unilateral nodular diabetic glomerulosclerosis: recurrence of an experiment of nature. Am J Nephrol 7: 55-59

33. Pettitt DJ, Knowler WC, Lisse JR, Bennett PH (1980) Development of retinopathy and proteinuria in relation to plasma-glucose concentrations in Pima Indians. Lancet II: 1050-1052

34. Feldt-Rasmussen B, Mathiesen ER, Deckert T (1986) Effect of two years of strict metabolic control on progression of incipient nephropathy in insulin-dependent diabetes. Lancet II: 13001304

35. Dahl-Jørgensen K, Brinchmann-Hansen O, Hansen KF et al. (1986) Effect of near-normoglycaemia for two years on progression of early diabetic retinopathy, nephropathy and neuropathy: the Oslo Study. Br Med J 293: 1195-1199

36. Parving H-H, Hommel E, Mathiesen E et al. (1988) Prevalence of microalbuminuria, arterial hypertension, retinopathy and neuropathy in patients with insulin dependent diabetes. Br Med J 296: $156-160$

37. Damsgaard EM, Frøland A, Jørgensen OD, Mogensen CE (1990) Microalbuminuria as predictor of increased mortality in elderly people. Br Med J 300:297-300

38. Yudkin JS, Forrest RD, Jackson CA (1988) Microalbuminuria as predictor of vascular disease in non-diabetic subjects. Islington Diabetes Survey. Lancet I: 530-533

39. Mattock MB, Keen H, Viberti GC et al. (1988) Coronary heart disease and urinary albumin excretion rate in Type 2 (non-insulin-dependent) diabetic patients. Diabetologia 31: 82-87

40. Allawi J, Jarrett RJ (1990) Microalbuminuria and cardiovascular risk factors in Type 2 diabetes mellitus. Diab Med 7: 115-118

Received: 31 January 1991

and in revised form: 6 May 1991

Dr. M.-A. Gall

Hvidöre Hospital

Emiliekildevej 1

DK-2930 Klampenborg

Denmark 